\title{
When Pandemic Threat Does Not Stoke Xenophobia: Evidence from a Panel Survey around COVID-19*†
}

Yang-Yang Zhou

\author{
Margaret Peters ${ }^{\S}$
}

Daniel Rojas

December 6, 2022

\begin{abstract}
Many studies have found that pandemics heighten anti-immigrant attitudes among host citizens. Yet, most of these studies were done in Global North countries where migrants are likely to differ from host citizens in terms of race, religion, and ethnicity. Within the Global South, migrants and hosts are more likely to share these characteristics. Do pandemics spark the same anti-immigrant sentiment in these contexts? Further, pandemics often bring economic restrictions and job loss, making it difficult to untangle concerns over disease from economic concerns. We examine the case of Venezuelan migrants in Colombia, who share many characteristics with host citizens, before and during COVID-19. Additionally, the Colombian government implemented a strict lockdown for several months, allowing us to focus on the economic effects of the pandemic. Using a panel experimental survey of 374 Colombians, supplemented by 550 new respondents at endline, we find no evidence that exposure to COVID-19 changes attitudes, even if respondents were directly affected. However, those who did not lose their jobs viewed Venezuelan migration more positively at endline.
\end{abstract}

Keywords: COVID-19, migration, refugees, xenophobia, Colombia, Venezuela

${ }^{*}$ We are grateful to colleagues at the Centro Nacional de Consultoria (CNC) for survey administration. We thank the UBC Comp-Can Workshop, ASU Political Economy Working Group, UCLA CSIM Seminar for helpful comments.

${ }^{\dagger}$ This research received institutional review board (IRB) approval from UCLA (\#19-001733) and UBC (\#H19-03288). Our Pre-Analysis Plan (PAP) was archived in the OSF repository https://osf.io/kuwch. All replication material, including R code and data, will be made available via Harvard University's Dataverse.

${ }^{\ddagger}$ Assistant Professor, Department of Political Science, University of British Columbia; Academy Scholar, Harvard Academy for International and Area Studies; and CIFAR Azrieli Global Scholar, yangyang.zhou@ubc.ca, www.yangyangzhou.com

§Associate Professor, Department of Political Science, UCLA, mepeters@ucla.edu, www.maggiepeters.com

IPh.D. Candidate, Department of Political Science, University of British Columbia, daniel.rojaslozano@ubc.ca 


\section{Introduction}

How does exposure to COVID-19 affect attitudes of host citizens towards migrants? ${ }^{1}$ Several early studies of this pandemic have found that it has increased anti-immigrant and anti-minority attitudes and behaviors. Similarly, there is a larger literature, including the behavioral immune system (BIS) hypothesis, that has linked disease threat to increased xenophobia in general (e.g. Green et al., 2010; Dionne and Seay, 2015; Prati and Pietrantoni, 2016; Aarøe, Petersen and Arceneaux, 2017; Marshall and Shapiro, 2018; Reny and Barreto, 2020; Lu et al., 2021).

In addition to the BIS mechanism, pandemics - and especially the COVID-19 pandemic - may affect views on immigration through their effects on the economy. Most countries required workplaces to shut down at least for a time and many countries fell into at least a short recession. Scholars have found that recessions (Goldstein and Peters, 2014), and job losses (Hopkins, Margalit and Solodoch, 2022) can lead to an increase in anti-immigrant sentiment. This suggests that the economic effects of the pandemic could be (partly) responsible for changes in opinion.

Yet, most of these studies focus on host attitudes in the Global North, where migrants are likely to be of a different race, ethnicity, and/or religion than host citizens. These differences heighten the effect of disease threat on anti-immigrant sentiment because individuals cue otherness from appearance (Esses and Hamilton, 2021; Freitag and Hofstetter, 2022; Suhardiman et al., 2021). In contrast, large number of migrants, particularly the vast ma-

\footnotetext{
${ }^{1}$ Throughout this paper, we use "migrants" and "refugees" interchangeably to describe (largely international) migrants who leave due to crises. Technically, "refugee" is a limited legal construct created at the end of the Second World War, which many of the Venezuelan migrants in our study would not qualify as. However, the UNHCR recognizes the over 4.9 million Venezuelan migrants as "forcibly displaced." Even a "voluntary" versus "forced" migration distinction is problematic as it does not recognize the nuance in migrant decision-making and it takes agency from migrants (Crawley and Skleparis, 2018; Mourad and Norman, 2020; Holland and Peters, 2020; Hamlin, 2021). To move away from this dichotomy, we focus on all migrants who leave due to violence, poverty, natural disaster, and so on, regardless of whether they qualify for legal refugee status and refer to them as migrants, while recognizing that this is not a value-neutral term either.
} 
jority of whom experiencing displacement, move within the Global South. Here, they are likely to share these characteristics with host countries, suggesting the BIS should not hold in these contexts. These countries also have weaker social safety nets, which may heighten concerns over the loss of income among host citizens. Thus, if the pandemic affects attitudes through an economic channel, we might be more likely to find this effect in a Global South context.

We assess whether COVID-19 exposure has changed attitudes in the context of Colombian citizens' attitudes toward Venezuelan migrants. As of 2021, when we fielded our endline survey, there were 6 million Venezuelans living outside their country due to the political crises under presidents Hugo Chávez and Nicolás Maduro and related economic collapse. With over 1.7 million Venezuelans, Colombia is the second-largest refugee hosting country in the world. ${ }^{2}$ After the outbreak of COVID-19 in March 2020, the government imposed a national quarantine and lockdown alongside a series of economic policies for vulnerable Colombian citizens and firms, but it also upheld its commitment to hosting Venezuelans. In February 2021, President Iván Duque expanded the regularization program to practically all Venezuelan migrants, extended it from two to ten years, and gave them all access to COVID-19 vaccines and healthcare.

While migrant-hosting policies in Colombia have been generous (Ibánez et al., 2021), Colombian citizens on average hold negative views toward Venezuelan migrants (Rozo and Vargas, 2021; Holland, Peters and Zhou, 2021). In this paper we ask whether these views worsened during the pandemic. Similar to the Global North, it may be the case that views have worsened as migrants have been scapegoated as sources of contagion or as competitors in the labor market. On the other hand, given the similarities between Colombians and Venezuelans, views may not have shifted.

\footnotetext{
${ }^{2}$ https://www.unhcr.org/en-us/venezuela-emergency.html
} 
Prior to the outbreak of COVID-19, in fall 2019, we conducted face-to-face surveys with about 1,000 Colombians living in two moderately large cities, Cali and Cúcuta, on their attitudes about Venezuelan refugees. In winter 2021, we were able to re-interview 374 of those respondents using computer-assisted telephone interviewing (CATI). Thus, we provide evidence on the link between concerns about disease and xenophobia in the context of a massive refugee crisis by examining the change in views within respondents rather than over different cross-sections. This allows us to better identify whether COVID-19 has changed attitudes.

To supplement this sample, we also surveyed 550 new respondents that were stratified sampled based on the demographics of the 2019 baseline respondents we were not able to recontact. For the 2021 (endline) survey, we also embedded an experimental component in which we randomized the order between question blocks asking about COVID-19 versus migration attitudes; those who received the COVID-19 question block first ("COVID-first") are therefore primed to think about how the pandemic has affected them and their family before answering questions about migration attitudes. Building on prior studies linking disease threat to increased xenophobia, we test the hypothesis that Colombians with greater COVID-19 exposure will be more opposed to migrants, especially among those who have had COVID or have had family members with COVID and therefore may be more primed to think about the disease as a threat (our survey was fielded prior to the widespread availability of vaccines and treatments). We also test whether job or income less affected views.

Counter to the studies in the Global North, we find little evidence that the COVID-19 threat leads to more anti-migrant attitudes in this context. We present four types of analyses. First, we descriptively show that at endline, the majority of our respondents (new and panel) felt that Venezuelan migrants obeyed COVID protocols (60\%) and deserved sympathy (76\%). Additionally, substantial numbers of respondents thought that compared to Colombians, 
Venezuelan migrants were no more likely to spread COVID-19 (44\%), were not receiving more government assistance (50\%), and were not using up healthcare resources (43\%). $38 \%$ of our respondents recognized that Venezuelans are essential workers in Colombia. Experimentally, receiving the COVID-first questions had no effect on these beliefs. Second, for the panel respondents, we use a two-period, two-group (COVID-first treatment versus control) difference-in-difference analysis. ${ }^{3}$ These estimates show that at endline, treated respondents are more supportive of the borders remaining closed and that Colombia needs more aid to handle migrants. However, they are no more likely to hold anti-migrant attitudes nor feel economically competitive with migrants. Third, when we bring in the new respondents, we show that cross-sectionally, there are also no effects of receiving the COVID-first treatment on anti-migrant attitudes. In fact, in some cases, treated respondents are more empathetic towards migrants.

Additionally, we explore subgroup effects by whether the respondent or their family were impacted by COVID-19 in terms of health or employment/income loss. We still find little evidence that having had COVID-19 or having had a close family member with the disease affects migration beliefs. Nonetheless, we find that those who have not been economically impacted by the lockdowns were more open and sympathetic towards migrants, suggesting that being able to economically weather the pandemic may increase empathy towards others. Lastly, we reweight our survey using nationally representative weights, as well as compare similar questions to recent nationally representative surveys from Innovations for Poverty Action (IPA), Latinobarometer, and LAPOP; we find that our reweighted surveys produces the same substantive results and our survey respondents share similar experiences with COVID and similar views about immigration, which should allay fears that our results are

\footnotetext{
${ }^{3}$ Because our analyses compares two groups across two time periods, it is not subject to recent econometric criticisms of difference-in-differences models, which focus on multiple groups treated at different points over time
} 
driven by our particular sample.

Our findings encouragingly show that prejudice towards outsiders is not an inevitable repercussion of pandemics. In our discussion of the results, we theorize that stability or even increase in support for immigrants may be a result of the political environment. Politicians in the Global North often blamed China and Chinese citizens and immigrants for the disease, with President Trump going as far as calling it the "Kung Flu." Yet, other migrants in the Global North were not immune: many right leaning politicians portrayed asylum-seekers to the US and elsewhere as carriers of the disease. Yet, we find little discussion among elites in Colombia discussing Venezuelan migrants in this light. Whereas cases of pandemicdriven xenophobia can be traced to politicians' scapegoating migrant groups (Devakumar et al., 2020; Freier and Vera Espinoza, 2021), our study points to a case in which the state announced support for migrants in a time of crisis. Our findings are also in line with recent research (conducted in the US and Europe) showing that attitudes towards immigration are remarkably stable over time (Kustov, Laaker and Reller, 2021).

This research ties into the much larger literature on attitudes towards immigration. While most of that literature has focused on attitudes in the Global North, our paper examines a Global South context. Additionally, much of the literature only interviews respondents at one time - our paper provides a panel across time allowing us to examine how different factors might change opinions (see Goldstein and Peters 2014 for similar panel surveys).

\section{How Pandemics might affect Immigration Attitudes}

We review two theories by which the pandemic could have affected opinions on immigration: theories based on a direct link between disease and anti-immigrant sentiment and those based on an indirect link through the economic effects of lockdowns. Of course, there is also the null hypothesis that the pandemic has had little to no effect on views on immigrants. As 
noted, recent research shows that attitudes towards immigration are remarkably stable over time (Kustov, Laaker and Reller, 2021). Similarly, Goldstein and Peters (2014) found that anti-immigrant attitudes only increased slightly during the Great Recession and recovered quite quickly.

\subsection{Direct links between the pandemic and anti-immigrant sentiment}

This study builds on research across the social sciences that examines the link between fears of disease with xenophobia, support for stricter immigration policy, and dehumanization of migrants (e.g. Green et al., 2010; Aarøe, Petersen and Arceneaux, 2017; Marshall and Shapiro, 2018; Schaller and Park, 2011). There are a few different hypothesized mechanisms that link fear of a disease with discrimination towards outgroups, and especially towards immigrants. The first mechanism is based on the "behavioral immune system," a set of psychological mechanisms that developed to keep humans away from pathogens. The threat of a pathogen, then, leads people to avoid what might carry that pathogen, including avoiding groups of people thought to carry the disease (Schaller and Park, 2011).

Those that feel vulnerable to a disease, then, are likely to discriminate against immigrant groups thought to be disease carriers (Faulkner et al., 2004; Green et al., 2010; Kim, Sherman and Updegraff, 2016; Prati and Pietrantoni, 2016). As articulated by Douglas (1966), biolog-

ical fears around pollution and contagion tend to become universal social concerns around insider and outsider status, with outsiders seen as disease carriers. These societal concerns around impurity then can be connected with immigration, an obvious outsider group, and refugees and asylum-seekers are, in particular, often linked to disease and threats to national security (Malkki, 1995).

A second mechanism that ties disease to immigrants is how immigrants are framed, even in times without a major outbreak. Often immigrants are framed by anti-immigration 
politicians and activists as pathogens infecting the nation (Marshall and Shapiro, 2018; Brown et al., 2019). For example, anti-immigrant politicians, like Donald Trump, have used rhetoric about an "infestation." ${ }^{4}$ In 2015, long before the COVID-19 pandemic, Trump had claimed that Mexicans bring "tremendous infectious disease" to the US. ${ }^{5}$ Use of this type of rhetoric during normal times may prime individuals to connect a pandemic to immigrants.

Further, the social boundaries between majority and minoritized groups intensify during outbreaks of unknown diseases; in-group members blame out-group members as a way to regain a sense of control (Dionne and Turkmen, 2020). Similar to what we might call "Travel Ban Theater" ${ }^{-}$-in which politicians enact travel bans from countries with disease outbreaks after the infection has spread - taking political action against minoritized groups is "doing something" in the face of a difficult-to-solve threat. The perceived cultural difference between majority group and immigrant/minority group seems to matter as well; the threat is less intense or non-existant for immigrants who are seen as less distinct (Faulkner et al., 2004; Schaller, Murray and Hofer, 2021), which may be the case in our study. Regardless of mechanism, greater exposure to an epidemic is likely to trigger greater anti-immigrant sentiment (Hartman et al., 2020; Wamsler et al., 2020), at least to more unfamiliar or more culturally distant groups.

We see this connection between disease outbreaks and anti-immigrant sentiment throughout history. At the turn of the 20th century, Irish, Italian, Jewish, Chinese, and Mexican immigrants in the US were blamed for outbreaks of cholera, polio, tuberculosis, bubonic plague, and typhus, respectively (Kraut, 1995; Power, 1995; Markel, 1999; Mckiernan-González, 2012). Immigrants to the US have further been stigmatized as vectors of diseases despite these fears being empirically unfounded (Markel and Stern, 2002). In response to

\footnotetext{
${ }^{4}$ https://www.cnn.com/2018/07/03/politics/trump-ms13-illegal-immigration-rhetoric/index.html

${ }^{5}$ https://www.theguardian.com/us-news/2015/jul/06/donald-trump-mexican-immigrants-tremendousinfectious-disease

${ }^{6}$ https://www.thelancet.com/journals/lancet/article/PIIS0140-6736(21)02752-5/fulltext
} 
these fears, at the beginning of the 20th century, the US government implemented rigorous medical scrutiny procedures for immigrants, in hopes of reducing the economic burden such immigrants might place on society. These quarantines and medical inspections, especially, at border stations on the US-Mexico border, led to stereotyping all (non-European) migrants as vectors for disease. Importantly, these policies underscore how politicians often exacerbated xenophobia by connecting immigrants to disease (Markel and Stern, 2002). More recently, the HIV/AIDS-epidemic and Ebola outbreak have led to the discrimination and exclusion of migrants from Caribbean and African nations (Fairchild and Tynan, 1994; Dionne and Seay, 2015), similar to previous immigrant exclusions. ${ }^{7}$

With respect to the current COVID-19 pandemic, several recent papers point to an increase in prejudice and xenophobia, particularly towards people of East Asian descent (whether native- or foreign-born; Coates, 2020; Freitag and Hofstetter, 2022; Ng, 2020; Wamsler et al., 2020). In a panel study, Yamagata, Teraguchi and Miura (2020) find that anti-foreigner attitudes increased over the course of the early pandemic in Japan. In the US, Reny and Barreto (2020) find growing support for xenophobic policies related to the pandemic when these policies target Asians rather than other immigrant groups.

Beyond affecting people of Asian descent, COVID-related xenophobic sentiments can transfer to other migrant and minority groups (e.g. Jillson, 2020; Freier and Vera Espinoza, 2021). A recent vignette experiment conducted in the US found that priming COVID-19 increases prejudice not only toward Asians but also toward Hispanics (Lu et al., 2021). This extended prejudice is particularly relevant in contexts of preexisting economic and social inequalities between citizens and migrants, and where migrants, such as Venezuelans in Colombia, are eligible for social welfare benefits. Qualitative evidence in Latin America points to heightened concerns over economic competition and welfare resources. For ex-

\footnotetext{
${ }^{7}$ See Dionne and Turkmen (2020) for a thorough review.
} 
ample, the perception of immigrants as a burden to public services increased opposition to immigration during the pandemic in Peru, while in Chile, both the government and media outlets attributed irregular migration as a driver of the increasing number of COVID-19 cases, thus sparking xenophobic attitudes in the host population (Freier and Vera Espinoza, 2021).

On the other hand, through a survey in Germany that spans pre- and post-COVID outbreak, Drouhot et al. (2021) find that attitudes towards diversity and toward Asian-origin populations have remained stable. They argue that although there are surges in racist incidents and hate crimes, these xenophobic actions are not reflective of the wider public opinion. Daniels et al. (2021) conduct a survey experiment in California to test whether priming respondents with the pandemic increase negative attitudes toward migrants. They find that the COVID-19 prime did not increase xenophobic attitudes, and in fact, attitudes toward immigrants' contributions became more positive, which they attribute to their Asian-American and Latino respondents, two minoritized communities that make up large segments of the Californian population. These findings suggest that whether disease threat will engender xenophobia is highly contextual, which we discuss further in the following subsection. Finally, in the US, Gadarian, Goodman and Pepinsky (2022a; 2022b) find that while there was increased support for travel bans and anti-immigration policies, this support was driven by racial resentment and partisanship, not fear of the disease itself.

\subsection{Indirect links between the pandemic and opinions on immigration}

Unlike pandemics of the recent past, including Ebola and AIDS, the COVID-19 pandemic led to lockdowns and shuttering of businesses in most countries in the world, ${ }^{8}$ leading to a global recession. ${ }^{9}$ It could be the case that the economic effects of the pandemic and, not

\footnotetext{
${ }^{8}$ https://ig.ft.com/coronavirus-lockdowns/

${ }^{9}$ https ://www . worldbank .org/en/news/feature/2021/06/08/the-global-economy-on-track-forstrong-but-uneven-growth-as-covid-19-still-weighs
} 
the pandemic per se, led to increased anti-immigrant sentiment. Large economic recessions, like the Great Depression, have seen an increase in anti-immigrant sentiment; but the link between recessions and opposition to immigration is not automatic (Peters, 2017). Instead, individuals' exposure to individual economic losses, and not general economic conditions, seems to drive increases in anti-immigrant sentiment. For example, Goldstein and Peters (2014) find that in their panel those who perceive they have suffered losses increase their opposition to immigration. Hopkins, Margalit and Solodoch (2022), also using a panel survey in the US, show that job losses and decreases in income lead to increased anti-immigrant sentiment. Yet, this finding only held for White men; the authors argue that as the dominant social group, the loss of status that comes with job and income loss increases anxiety towards outsider groups. Around the COVID-19 pandemic Dipoppa, Grossman and Zonszein (2021) show that hate crimes towards Asian migrants increased substantially after the start of the pandemic, but that it was economic concerns rather than the threat of infection that triggered the violence. Similarly, Dhanani and Franz (2021) found that frames around the economic effects of COVID-19 increased anti-Asian sentiment but concerns about the health effects did not. ${ }^{10}$ Building on this literature, it could be the case that it is job/income loss due to the pandemic rather than fears over the disease itself that could lead to an increase in anti-immigrant sentiment.

\section{Context: Venezuelan Migrants in Colombia}

Economic and political turmoil in Venezuela has led to large arrivals of migrants into neighboring countries, particularly Colombia. Colombia has received the largest number of migrants from Venezuela, with 1.7 million registered migrants in January 2021, when we fielded our endline survey. Migration accelerated substantially post-2015, as humanitarian

\footnotetext{
${ }^{10}$ They also found that framing the disease as coming from Asia increased anti-immigrant sentiment (Dhanani and Franz, 2021).
} 
conditions worsened under President Nicolás Maduro. While 48,714 Venezuelan arrived to Colombia in 2015, 870,093 came in 2018, and 189,883 in 2020. ${ }^{11}$ Most Venezuelans are fleeing a humanitarian crisis, but do not meet the formal international legal definition as refugees as articulated by the UNHCR. ${ }^{12}$

The Colombian government has largely welcomed Venezuelan migrants. In July 2017, Colombian President Santos created special residency permits, El Permiso Especial de Permanencia (PEP), which grant Venezuelans two years of legal residency, the right to work in the formal sector, and access to the social assistance program Sistema de Seleccion de Beneficiarios Para Programas Sociales (Sisbén). This includes subsidized healthcare, public education, cash transfers, financial services, and access to mobile phones. During the first two waves of the PEP program, approximately 182,000 Venezuelans regularized their status (Bahar, Ibáñez and Rozo, 2021). Having PEP status allowed these Venezuelan migrants to have better health outcomes, less food insecurity, and were less likely to be evicted during the pandemic (Ibánez et al., 2021). In February 2021, right after our survey was fielded, President Duque announced a second, more generous regularization program for Venezuelans.

\subsection{Impact of COVID-19 on Colombia}

Colombia reported its first confirmed case of COVID-19 on March 6, 2020. On March 14, Colombia closed its borders with Venezuela and declared a country-wide quarantine starting

\footnotetext{
${ }^{11}$ IOM, Migration Trends in the Americas, July 2018; Migración Colombia 2020.

${ }^{12}$ They may be eligible for refugee status under the Cartagena Declaration under the criteria of "other circumstances that have seriously disturbed the public order." Further, investigations have revealed alarming extrajudicial executions of political opponents. UN Human Rights Council, "Report of the United Nations High Commissioner for Human Rights on the situation of Human rights in the Bolivarian Republic of Venezuela," July 5, 2019. Nonetheless, the UNHCR has urged receiving countries to provide appropriate international protections in line with the 1951 Refugee Convention because "while individual circumstances and reasons for these movements vary, international protection considerations have become apparent for a very significant proportion of Venezuelans." UNHCR, "Guidance Note on the Outflow of Venezuelans," March 2018, http://www.refworld.org/docid/5a9ff3cc4.html.
} 
March 25. ${ }^{13}$ Many of these restrictions remained in place through spring and early summer 2020, when they were rolled back as cases fell. Yet, most were brought back due to a late 2020 surge in cases. In early January, when our survey was fielded, renewed stay-at-home and work-from-home restrictions were in place. The border, however, did not reopen and remained essentially closed until May 2021 (Hale et al., 2020).

Venezuelan migrants were deeply affected by the lockdown. While the Colombian government announced a moratorium on evictions of Venezuelans, this was always not enforced. Without access to daily informal work during the lock-down, thousands of migrants were unable to pay rent and buy food, and were thus pressured to flee back to Venezuela. ${ }^{14}$

During this time, media reports also pointed to increasing xenophobia against Venezuelans. For example, the Economist reported, "hundreds of Bogotanos have protested against plans to house migrants in sports facilities. Along the border, false reports of Venezuelans trying to break into gated neighbourhoods, spread through Facebook, prompted police to deport some." 15 The same article described how some mayors were exploiting the crisis and stoking anti-migrant sentiment in order to close shelters and bar migrants from entering their towns. This suggests that we should find increased opposition to Venezuelan migrants. On the other hand, given the media's reporting bias, these incidences may not be indicative of the true change in support.

As of January 12, 2021 when our survey went into the field, there had been over 1.8 million confirmed cases in Colombia and over 46,000 deaths. ${ }^{16}$ There have been many more cases in the province around Cali (with almost 150,000 cases) than around Cúcuta (with

\footnotetext{
${ }^{13}$ http://www.mixedmigration.org/wp-content/uploads/2020/05/099_covid_snapshot_LAC_en. pdf

${ }^{14}$ https : //www.npr.org/2020/04/28/846945447/thousands-of-migrants-head-back-tovenezuela-to-flee-colombias-covid-19-lockdown

${ }^{15}$ https : / www . economist . com/the-americas/2020/04/30/colombia-cools-on-venezuelanrefugees

${ }^{16}$ COVID-19 data is from Dong, Du and Gardner (2020).
} 
about 44,000 cases). At the start of our survey, there were about 8,000 active cases around Cali and 2,000 around Cúcuta. While the incidence rate around Cali is higher (at about 3,300 per 100,000 versus 2,900 per 100,000 in Cúcuta), the case-death rate has been higher in Cúcuta (at 5\% versus 3\% in Cali). As with most of the COVID-19 data, this is likely an under-count of the number of infected due to lack of testing and, possibly, the number who have died due to lack of reporting of deaths that occurred outside of a hospital.

\section{Research Design: Panel Survey with Randomized Modules}

\subsection{9 pre-COVID Baseline Survey}

From August-October 2019, we conducted a survey of Colombian citizens in Cali and Cúcuta, two moderately populated cities with substantial concentrations of Venezuelan migrants. Cúcuta is located at the Venezuelan border and therefore has absorbed the largest fraction of Venezuelan migrants, particularly poorer migrants without the resources to travel further. This border has long been permeable, with Colombians crossing into Venezuela to buy (and smuggle) cheap gasoline and subsidized goods, and Venezuelans working and trading on the Colombian side (Villegas et al., 2009). The population in Cúcuta is primarily mestizo, with less than $3 \%$ identifying as Afro-descendent. Cali is a coastal city, with smaller concentrations of Venezuelans but large internally displaced populations. It has a large Afrodescendent population (roughly 20 to $25 \%$, according to the 2015 census). There are about 750,000 Colombians living in Cúcuta and 2.4 million in Cali.

In each city, we surveyed about 500 Colombians, for a total of 1005 baseline respondents. A respected survey firm in Colombia (CNC) ran the face-to-face survey. We conducted a simple random household sample, choosing a random start location and using a skip rule. ${ }^{17}$ The survey lasted approximately 45 minutes, and respondents received roughly $\$ 5$ USD in

\footnotetext{
${ }^{17}$ We excluded Colombian-Venezuelans from our sample, given that they likely have different access to services and views on migration as Colombian citizens.
} 
compensation.

In this pre-COVID survey, we asked about attitudes towards Venezuelan migrants (Migration Attitudes block), and we found that $92 \%$ of Colombians already believed that "there are too many Venezuelans in the country," with $66 \%$ supporting border closure. Back then, Colombians were primarily worried about the effects on Venezuelans on the job market $(72 \%$ feared Venezuelans would take jobs from Colombians), and on the ability of the government to provide services $(78 \%)$. They were also very concerned about how Venezuelans from a socialist regime might impact politics in a country where the majority of voters support the center right. Unlike in high-income country contexts, our Colombian respondents were relatively unconcerned about whether Venezuelans were high- or low-skill and unconcerned about the racial and cultural effects of these migrants.

\subsection{Follow-up Survey}

We ran a follow-up survey from January-February 2021 by recontacting the 2019 baseline respondents, and supplementing them with a sample of new respondents. In the baseline, we collected respondent phone numbers and asked if they would be willing to take a future survey with us; 853 had said yes. CNC used CATI (conducting the surveys by phone with the respondents while reading off the questions from Qualtrics) to attempt to re-interview all of those participants from fall 2019. We were able to recontact 374 respondents (44\%), 211 in Cali and 163 in Cúcuta.

In Section S1 of the Supplementary Information (SI), we conduct equivalence tests to assess which demographic covariates are different between attrited and panel respondents, and between panel and new respondents. ${ }^{18}$ From these tests, we can reject the null that

\footnotetext{
${ }^{18}$ We test whether the average values of pre-treatment variables are equivalent for attrited, panel, and new respondents. A current practice in the literature is to test for nonsignificant differences across groups of respondents. However, this approach tends to conflate low statistical power with negligible differences across groups. We follow Hartman and Hidalgo (2018) and set nonequivalence between groups as the null hypothesis. In this way, we test whether the difference between covariates in attrited and new respondents
} 

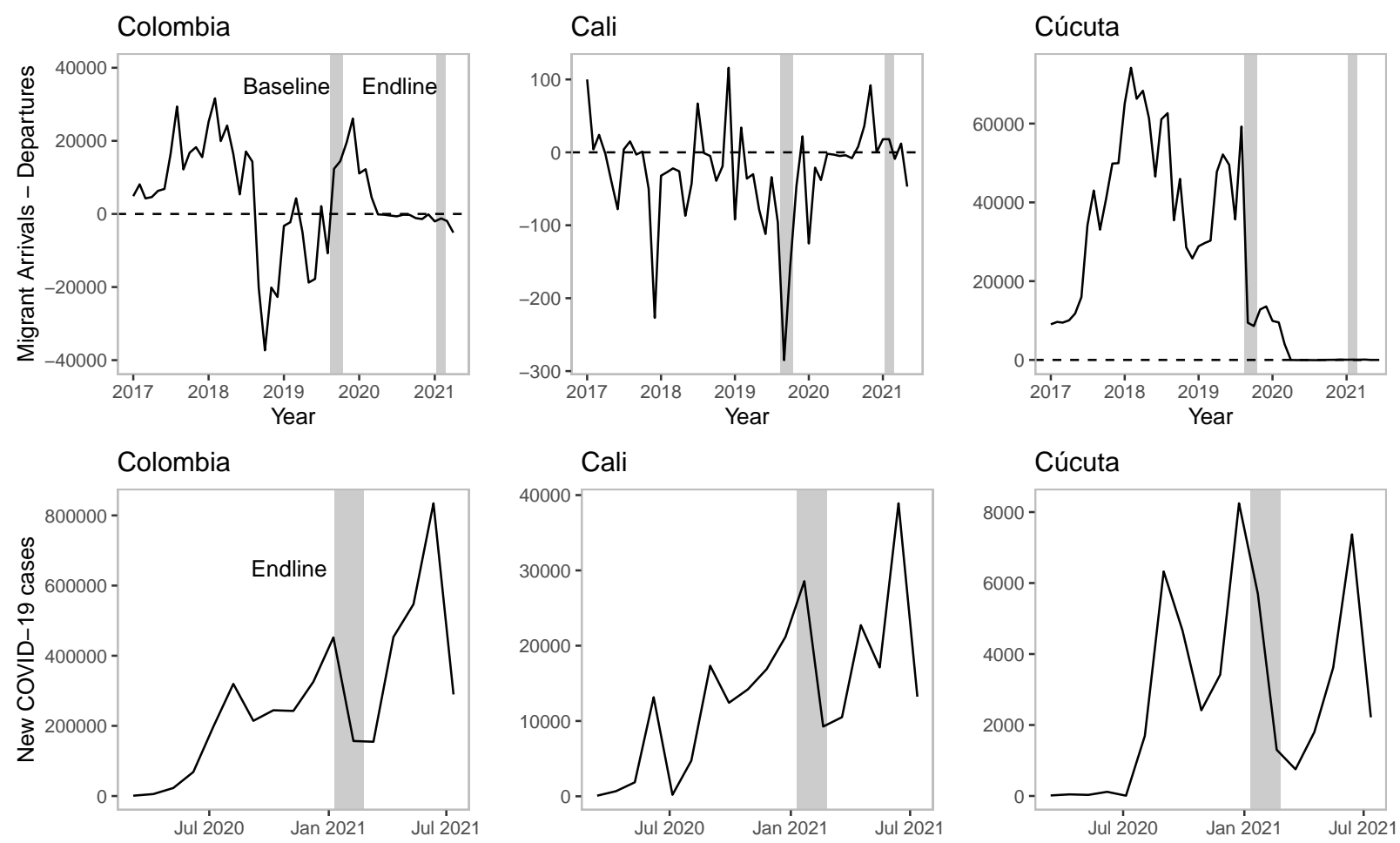

Figure 1: This figure shows the net arrivals of Venezuelan migrants (top row) and the number of new COVID-19 cases (bottom row) for Colombia nationwide, and our survey cities Cali and Cúcuta. The gray shading indicates when we conducted our baseline and endline surveys.

there is a difference between the attrited and panelist respondents in terms of their age, gender, race, religiosity, marital status, socioeconomic strata, and average wealth. However, we cannot reject the null in terms of city of residence, education, religion, and political ideology. Compared to attrited, panel respondents tend to be slightly more from Cali, more educated, Catholic, and ascribe to right-wing ideology. ${ }^{19}$ To supplement our panel sample, we also recruited 550 new participants. These new respondents were chosen to match the demographics of those who attrited. We matched within each city on gender, ethnicity, age bracket, and SEL (household socio-economic status) quotas.

SI Section S2 compares the demographic characteristics across the groups. Our respon-

is inconsequential for our analysis.

${ }^{19}$ Note that unlike in many Global North countries, right-wing idology in Colombia does not typically mean anti-immigrant. 
dents tend to be older (36.7\% are 55+), 59.4\% identify as women, $41.8 \%$ identify as Mestizo, and most have completed primary $(19.5 \%)$ or secondary $(32.6 \%)$ education. Most are in SEL strata $3(27.1 \%)$ or $4(10.6 \%)$, with on average 5 household items of the 14 we asked about (e.g. TV, stove, washing machine, etc.). While $42.4 \%$ are employed, of those, $57 \%$ have informal contracts. Most identify politically as center (38.4\%) or right $(25.2 \%)$, and religiously as Catholic (63\%) and very religious (70.1\%). Because we stratified sampled our new respondents, demographically they are very similar to our panelists.

Figure 1 shows the timing of our baseline and endline surveys in relation to net migrant flows (top row) and new COVID-19 cases (bottom row) nationwide and in our two survey cities. According to the UNHCR, in October 2020 (the latest month of statistics available before we fielded our survey), there were approximately 194,000 Venezuelans living in Norte de Santander, the province of Cúcuta, ${ }^{20}$ and about 59,000 Venezuelans living in Cali, a slight decrease from March 2020. ${ }^{21}$ The number of Venezuelans in Colombia is down by $6 \%$ in total due to the mandatory isolation restrictions. ${ }^{22}$ At endline, due to border closures, the number of new Venezuelan migrants was essentially zero.

The start of the endline also coincided with the peak of the second wave at the end of 2020. In January 2021 when we fielded our survey, the province in which Cali is located, there had been about 67,000 cases of COVID-19 and about 2,400 deaths and the in the province in which Cúcuta is located, there had been about 34,000 cases and 1,400 deaths for 2021. Although the number of new cases was declining, respondents were likely experiencing the consequences of this second wave.

In this endline survey, we presented two modules of survey questions. Our first module asked about the respondents and their families' exposure to the disease itself; the effects of the

\footnotetext{
${ }^{20}$ https://data2 .unhcr.org/en/documents/details/83911

${ }^{21}$ https://data2.unhcr.org/en/documents/details/83935.

${ }^{22}$ https ://data2 . unhcr.org/en/documents/details/83911
} 
public health restrictions on their economic circumstances; their views of the government's response to the virus; and where they get information about the virus (COVID block). We used questions similar to those being asked by scholars elsewhere to help increase our knowledge about the virus from around the world; specifically, we used questions similar to those developed by the IPA RECOVR survey in Colombia. For the second module, we asked our Colombian respondents the same questions we asked in 2019 about their opinions on Venezuelans and their effects in Colombia (Migration Attitudes block).

As a survey experimental component, we randomized whether the respondent received the COVID-19 block or the Migration Attitudes block first. We used the COVID-first module as an additional treatment, priming those respondents to think about their own COVID19 exposure when answering the Migration Attitudes questions. Thus, we estimated the effect of thinking about one's own level of COVID-19 exposure on attitudes about migrants, relative to respondents' pre-COVID attitudes about migrants. ${ }^{23}$

We note that this treatment is fairly subtle; COVID-19 was a daily issue for our respondents. It would have been difficult to design a treatment during this time that would have significantly increased the salience of COVID-19 and providing a treatement than downplayed the seriousness of it would have been unethical. Because we wanted to understand views during the pandemic, we did not want to wait until after the pandemic had subsided for fears that the responses would have been a product of bias recall.

\subsection{Survey Measures and Hypotheses}

Table 1 shows most of the survey questions we asked in the two main blocks. For the Migration Attitudes block, they were read as Yes/No statements, and within them, we

\footnotetext{
${ }^{23}$ In our PAP, we presumed that receiving the COVID-19 module first may affect migration attitudes, but not the other way around. We believe this is defensible since the COVID-19 module would only ask factual questions, not attitudinal. Nevertheless, we also report the mostly null effects of the Migration Attitude block on assessments of government responses to COVID-19 in the SI.
} 


\begin{tabular}{|l|l|}
\hline COVID block & Migration Attitudes block \\
\hline Have you had COVID-19? & There are too many Venezuelans in Colombia \\
\hline Has anyone in your family had COVID-19? & $\begin{array}{l}\text { Colombia should close its borders to } \\
\text { immigration immediately }\end{array}$ \\
\hline Do you know anyone who has had COVID-19? & $\begin{array}{l}\text { People should have the right to seek asylum, } \\
\text { including in Colombia }\end{array}$ \\
\hline Do you know anyone who has died from COVID-19? & $\begin{array}{l}\text { The international community is providing } \\
\text { enough aid for Colombia to handle the } \\
\text { Venezuelan migration situation }\end{array}$ \\
\hline $\begin{array}{l}\text { What are your top 3 concerns } \\
\text { associated with COVID 19? } \\
\text { Economic / Mental health / Physical health / } \\
\text { Security / Border / Religious }\end{array}$ & $\begin{array}{l}\text { The Venezuelan migration has been } \\
\text { a good thing for the average Colombian }\end{array}$ \\
\hline $\begin{array}{l}\text { Since March 2020, have you } \\
\text { Lost your job? / Lost wages? Spent savings? / } \\
\text { Borrowed money? / Relied on family and friends? }\end{array}$ & $\begin{array}{l}\text { The majority of migrants and refugees } \\
\text { in Colombia have integrated successfully }\end{array}$ \\
\hline $\begin{array}{l}\text { Have you received any govt assistance } \\
\text { that you did not before? If so, what? }\end{array}$ & Venezuelans take Colombians' jobs \\
\hline $\begin{array}{l}\text { Where do you rate the national govt } \\
\text { COVID-19 response? (1-5) }\end{array}$ & I compete with Venezuelans for work \\
\hline $\begin{array}{l}\text { How honest do you think the govt has been with } \\
\text { COVID-19 information? (1-5) }\end{array}$ & $\begin{array}{l}\text { Venezuelans living in Colombia are } \\
\text { deserving of our sympathy }\end{array}$ \\
\hline $\begin{array}{l}\text { Where do you rate the local govt } \\
\text { COVID-19 response? (1-5) }\end{array}$ & $\begin{array}{l}\text { Venezuelans are more likely to spread } \\
\text { COVID-19 than Colombians }\end{array}$ \\
\hline $\begin{array}{l}\text { Where do you rate the level of precautions that } \\
\text { Colombians are taking to face COVID? (1-5) }\end{array}$ & $\begin{array}{l}\text { Venezuelans are using scarce health resources } \\
\text { that Colombians need }\end{array}$ \\
\hline $\begin{array}{l}\text { Which sources of information do you trust when } \\
\text { it comes to COVID-19 prevention? }\end{array}$ & Venezuelans are essential workers during COVID-19 \\
\hline If available, will you take the vaccine? & $\begin{array}{l}\text { Venezuelans who are in Colombia now should } \\
\text { return to Venezuela until the emergency is over }\end{array}$ \\
\hline
\end{tabular}

Table 1: This table shows most of the survey questions (some paraphrased) for the two main survey blocks, which we randomized so the respondents who received the COVID block first were "treated" to think about COVID-19 before answering the Migration Attitudes block.

also randomized whether they were asked in the affirmative ("I compete with Venezuelans for work") or the negative ("I do not compete with Venezuelans for work"). For ease of interpretation, we rescaled all outcome variables on migration attitudes so that more positive (negative) estimates correspond to more inclusive (anti-migrant) attitudes.

It is possible that COVID has had direct, indirect, or no effect on opinions towards Venezuelan migrants. Thus, we test the following main hypotheses: ${ }^{24}$

Null Hypothesis a: For panel respondents, views towards Venezuelan migrants

\footnotetext{
${ }^{24}$ In our PAP, we also included hypotheses about the security situation, contact with Venezuelans, and views of Venezuelans as essential workers to examine alternative hypotheses that were prominent in the media. We found no support for these hypotheses; results are listed in the SI.
} 
will be the same during COVID compared to pre-COVID.

Null Hypothesis b: For both panel and cross-sectional respondents, Colombians' views towards Venezuelan migrants will be the same when primed to think about COVID compared to not.

Direct Effect Hypothesis 1a: For panel respondents, views towards Venezuelan migrants will be more negative towards migrants during COVID compared to pre-COVID.

Direct Effect Hypothesis 1b: For both panel and cross-sectional respondents, Colombians' views towards Venezuelan migrants will be more negative when primed to think about COVID compared to not.

Direct Effect Hypothesis 2: Respondents whose health or family's health have been affected by COVID will have more negative views. ${ }^{25}$

Indirect Hypothesis 3: Respondents who have experienced employment loss, income loss, or financial stress due to COVID will have more negative views.

\subsection{Empirical Strategy}

We conduct the following analyses. First, we descriptively examine how respondents were affected by COVID-19 in the past year, what precautions and decisions they made in response to COVID, how they evaluate the government's response, and where they get their information about COVID. These descriptive statistics will be useful to scholars and policymakers to understand the impacts of COVID-19 in Colombia generally.

Second, for the panel data of 374 respondents, our main two-period, two-group differencein-differences (DiD) analysis compares pre- and post-COVID migration attitudes between the experimentally treated and control groups; again, the treatment is whether the respondent received the COVID-first module on the survey. The equation we estimate is

$$
Y_{i t}=\alpha_{i}+\lambda_{t}+\beta T_{i t}+\gamma X_{i t}+\epsilon_{i t}
$$

\footnotetext{
${ }^{25}$ We are unable to conduct the DiD analysis for subgroups due to low power for the panelists.
} 
where $\alpha_{i}$ is a respondent fixed effect, $\lambda_{t}$ is a wave (2019 versus 2021) fixed effect, $T_{i t}$ is an indicator for whether an observation is in the COVID-first module (0 for all 2019 wave observations, and 1 for the COVID-first observations in the 2021 wave), and $X_{i t}$ is a vector of pre-treatment covariates for covariate adjustment. Standard errors are clustered at the respondent level.

Third, we conduct a cross-sectional analysis of all 924 respondents at endline - 374 panel respondents with the 550 new respondents, and we simply compare treated and control respondents. There, the equation we estimate is

$$
Y_{i}=\alpha+\beta T_{i}+\gamma\left(X_{i}-\bar{X}\right)+\lambda T_{i}\left(X_{i}-\bar{X}\right)+\epsilon_{i}
$$

where $T_{i}$ indicates whether observation $i$ is in the COVID-first module group, $X_{i}$ is a vector of pre-treatment covariates, and $\bar{X}$ is a vector of the mean values of the pre-treatment covariates.

Fourth, we run heterogeneous subgroup analyses on six variables - whether the respondents experienced COVID-19, had their health affected, experienced employment/incomeloss, have security concerns, have direct contact with Venezuelans, and view Venezuelans as essential workers. ${ }^{26}$

Finally, since our samples are not nationally representative, we first descriptively compare our respondents with recent nationally representative surveys conducted by IPA, Latinobarometer, and LAPOP in terms of their demographic characteristics, pandemic experiences, and attitudes toward migrants. We then reweight all our analyses using weights derived from the 2021 LAPOP survey.

\footnotetext{
${ }^{26}$ We cannot conduct this analyses within the panel because the number of panel respondents is too low to examine subgroup effects.
} 

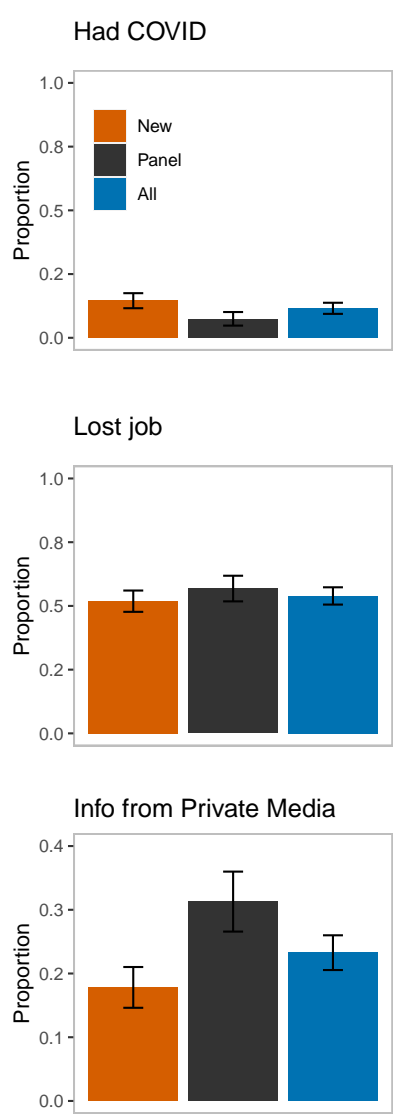
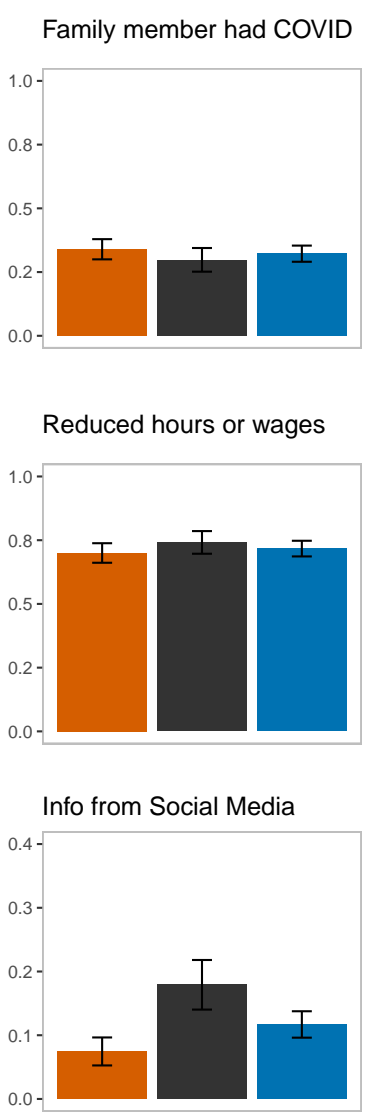
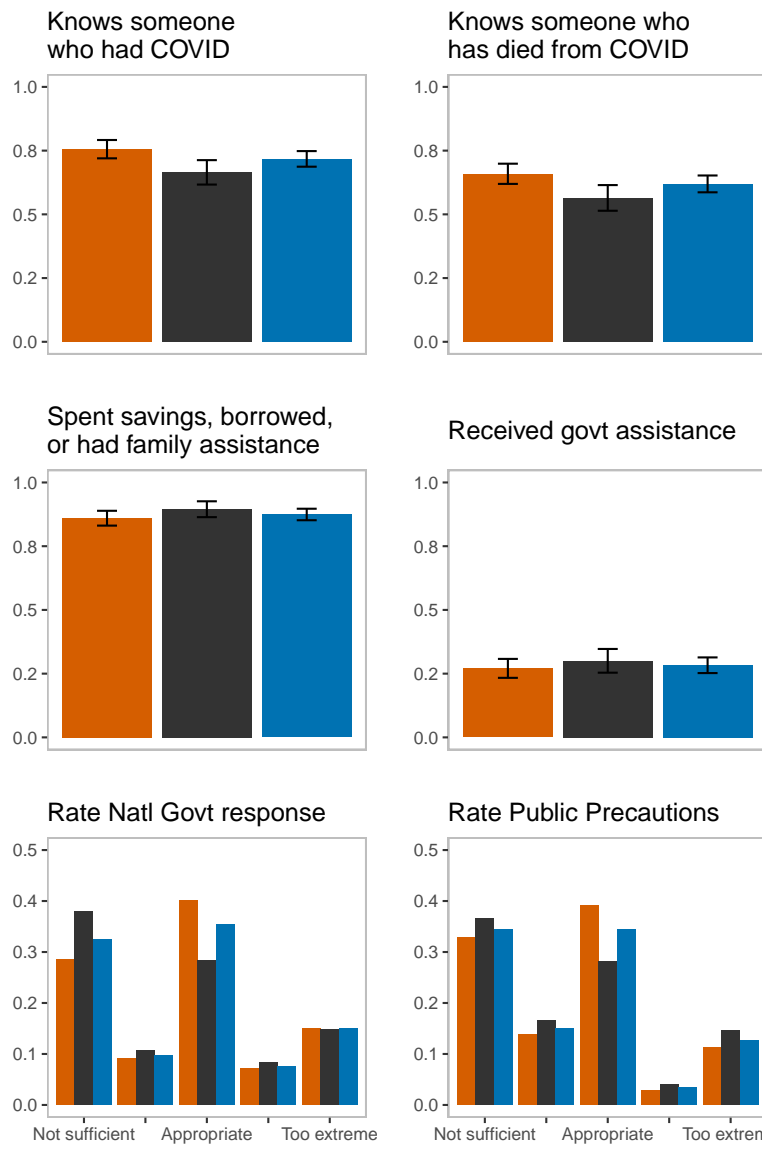

Received govt assistance
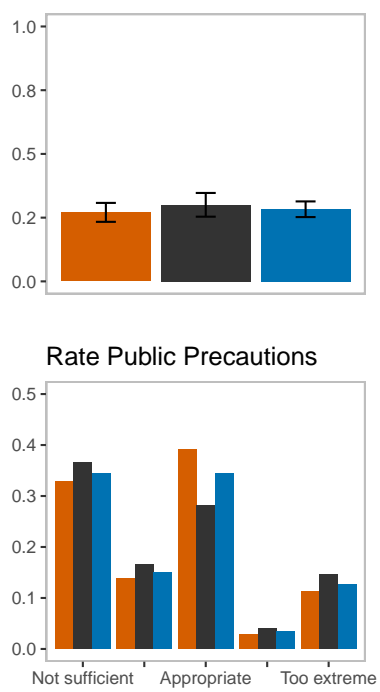

Figure 2: This figure shows the proportion of new (orange), panel (black), and all (blue) respondents who have been affected by COVID-19. All estimates include $95 \%$ CIs.

\section{Results}

\subsection{Experiences with COVID-19}

We begin the discussion of our results by summarizing our respondents' experiences with COVID-19, by group, in Figure 2. Across the groups (new, panel, all), the experiences are similar, thus we report the statistics for all respondents (blue). At endline, although $11.6 \%$ of respondents reported having COVID themselves, $32.2 \%$ had a family member who had COVID, and the vast majority at $71.8 \%$ knew someone with COVID and $61.9 \%$ knew someone who had died from COVID.

Half of our respondents lost their jobs, and $71.7 \%$ reported that they had their hours or 
wages reduced. About $87.4 \%$ had to spend their savings, borrow money, or get assistance from their family/friends in order to cover living expenses, and $28.3 \%$ reported receiving government assistance due to the pandemic.

With respect to where our respondents received their information about COVID-19, the two (out of 13) most popular sources were private media (23.3\%) and social media $(11.7 \%)$. And in terms of rating the national government's and public's response to COVID19, responses clustered around not sufficient and appropriate. Responses to rating the local government's response and government honesty about COVID-19 were similarly clustered.

\subsection{Diff-in-Diff Estimates for Panel Respondents}

We now turn to the main DiD results for our 374 panel respondents shown in Figure 3. For each of the groups of outcomes - (1) migration openness and (2) whether migrants compete for employment - the top panel presents the 2019 and 2021 means for the panelists with orange lines displaying the COVID-First treatment group and blue lines displaying the control group. The bottom panel displays both the post-pre estimates and the DiD estimates of the COVID-First treatment. We show results for two additional groups of outcomes-(3) whether migrants bring benefits and (4) whether migrants can integrate - in the SI Section S4.

First, more of our panelists thought that the border between Colombia and Venezuela should remain closed at endline; support for opening the border decreased by 9.4 percentage points (pp). This is unsurprising since border closures were a part of the health protocols. Nevertheless, general attitudes about openness towards Venezuelans remained relatively stable. There was no change over time for willingness to host Venezuelans in the respondent's city, and more respondents said that there were not too many Venezuelans in their country (12.6 pp). Support for the right to seek asylum remains very high at endline, but receiving 

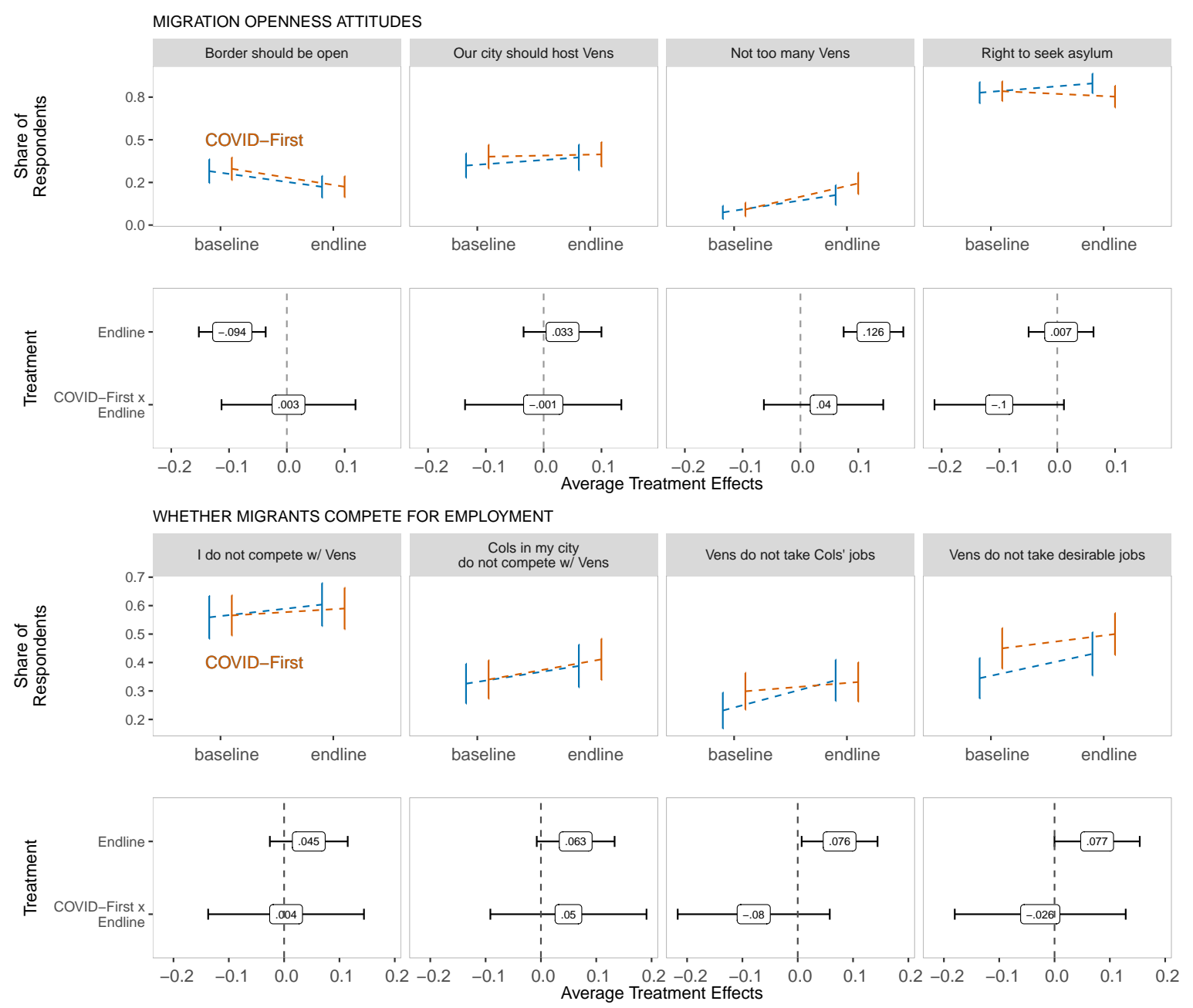

Figure 3: For each set of outcomes, the top plot shows over time means by COVID-First treatment (orange) vs. control (blue). The bottom plot shows the pre-post estimate and the Diff-in-Diff estimate of COVID-First interacted with period. All estimates include 95\% CIs.

the COVID-First prompt does decrease that support by -10 pp. Among our 16 outcomes, this is the only statistically significant DiD effect.

The lack of significance for the DiD results may be a product of our subtle survey prime treatment; perhaps COVID was already on everyone's minds, and it did not need to be explicitly primed. Nonetheless, because these are panel results and all respondents were affected by the pandemic, we have confidence that we are finding more support for the null hypothesis that opinions have been stable over the pandemic. 
Next, even though our respondents experienced great economic hardship due to the pandemic as described in the previous section, we find that, if anything, views of Venezuelan migrants as economic competitors have declined. Across all four outcomes, our respondents become more positive at endline compared to baseline. While the post-pre differences for whether individual respondents think they compete with Venezuelans or whether there is competition over jobs within their city are not statistically significant, agreement that Venezuelans do not take Colombians' jobs increased by $7.6 \mathrm{pp}$, and agreement that Venezuelans do not take desirable jobs increased by 7.7 pp. Nevertheless, once we correct for multiple hypothesis testing in SI Section S8, the Benjamini-Hochberg adjusted p-values for these two positive effects are larger than .05 .

For the remaining outcomes on whether migrants bring benefits or their ability to integrate, Figure S9 in the SI shows that there are no statistically distinguishable changes. We note that at baseline and endline, the belief that Venezuelans and Colombians share cultural ties are quite high.

\subsection{Cross-Sectional Estimates with all Endline Respondents}

Next, we focus on the cross-sectional analysis by comparing COVID-First treatment and control groups at endline with our panelists and new respondents together. In Figure 4, the top panel shows the group averages for COVID-First treatment (orange) vs. control (blue) across all, new, and panel respondents. The bottom panel shows the treatment effect of COVID-First by group. Similar to the DiD results, there are almost no effects of receiving the COVID-First module first. We also see that the results between our new respondents and panelists are similar across all outcomes, except for the right to seek asylum; the new respondents were less supportive of the right to seek asylum in general. These similarities

across all other outcomes suggest that the panel results above are not sensitive to non-random 

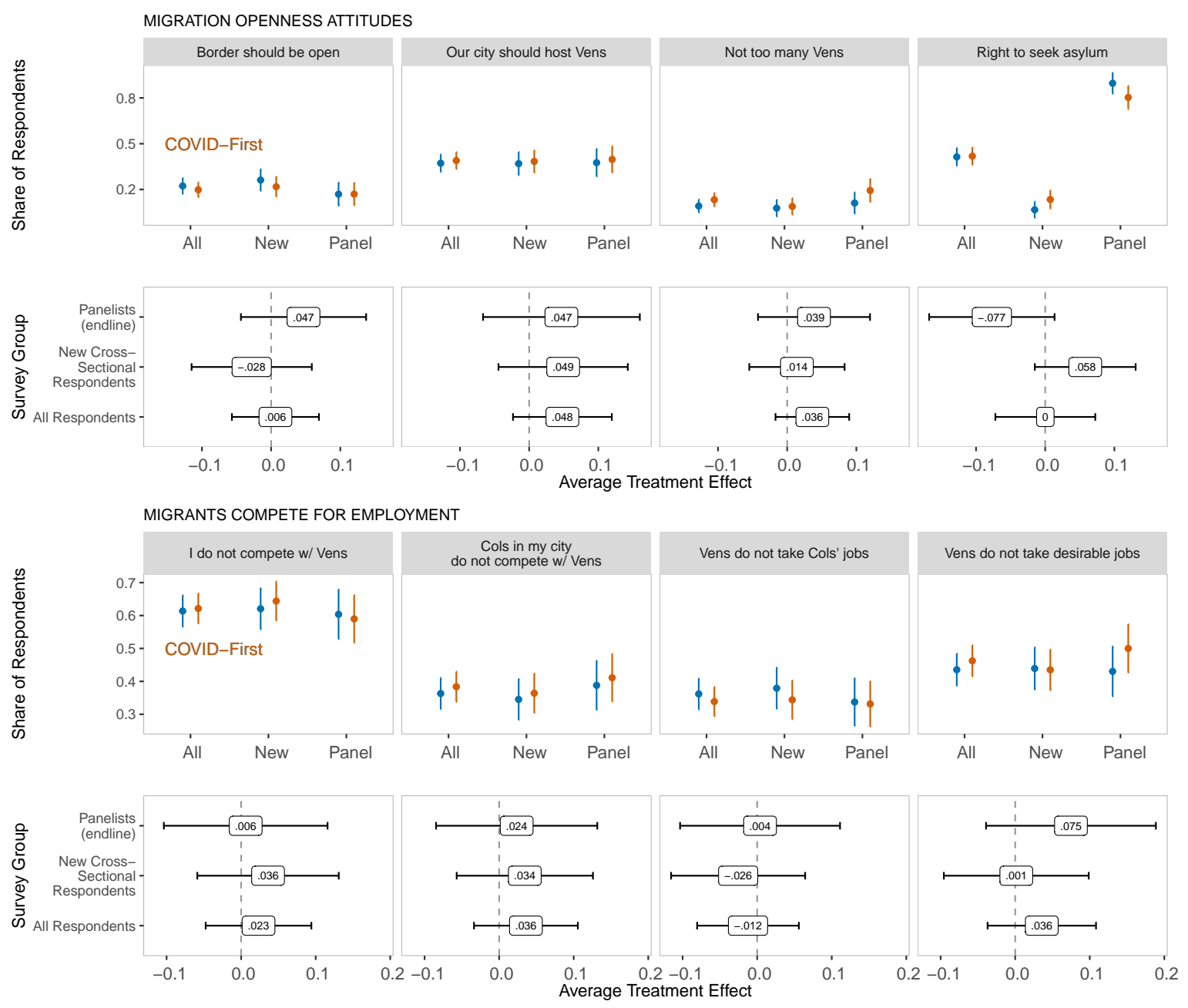

Figure 4: For each set of outcomes, the top plot shows endline means by COVID-First treatment (orange) vs. control (blue) across all, new, and panel respondents. The bottom plot shows the treatment effect of COVID-First by group. All estimates include $95 \%$ CIs.

attrition.

Overall, our respondents hold generally negative attitudes about Venezuelans. Respondents think that the border should be closed, that there are too many Venezuelans in Colombia, and that their city shouldn't host them. In line with results from the Global North, they worry about Venezuelans general effects on the labor market but not on their own labor market outcomes. They also think that the international community has not provided enough aid and that it has been harder to get access to services and there has been more 


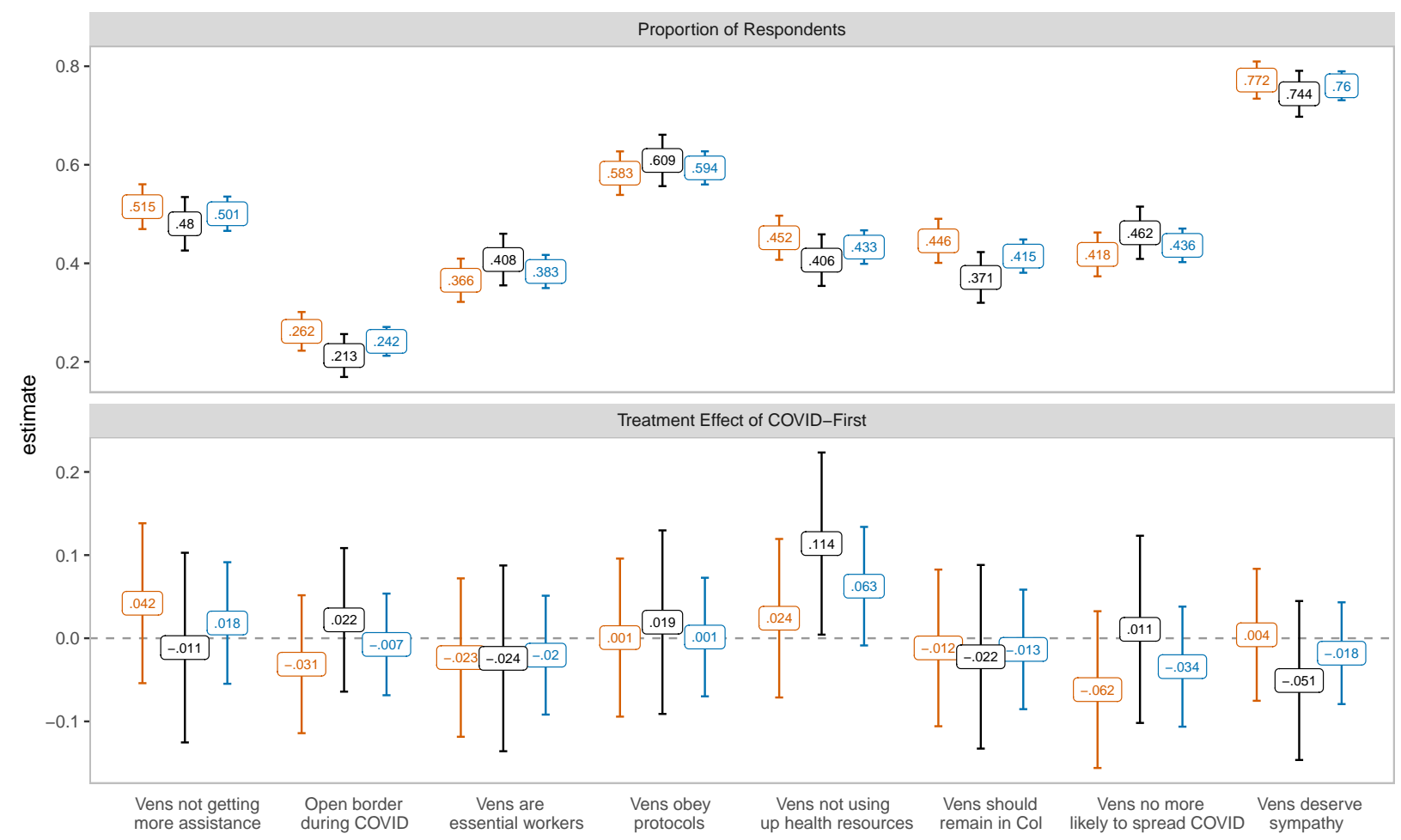

Figure 5: This figure shows questions about Venezuelan migrants and COVID asked at endline. The top plot shows the proportion of new (orange), panel (black), and all (blue) respondents who agreed with the statement. The bottom plot shows the treatment effect of COVID-First. All estimates include 95\% CIs.

conflict.

From Figure S10 in the SI, while they think that Colombians and Venezuelans share cultural ties, they are still worried about Venezuelans' ability to integrate. Nonetheless, while Colombians hold these negative views, it is not the case that these views change due to COVID-19. Priming our respondents to think about COVID before answering these questions had basically no effect on their attitudes. Thus, our results are in line with the null hypotheses.

\subsection{Migration and COVID Endline-only Attitudes}

Finally, we show responses about Venezuelan migrants in relation to COVID-19 asked only at endline. In the top panel of Figure 5 we present the proportion of respondents by 
group who agreed to each statement. As before, we do not find evidence of widespread antipathy towards Venezuelans. While $75.8 \%$ of respondents want the border to remain closed, 41.5\% believe that Venezuelans should remain in Colombia, and $76 \%$ say that Venezuelans deserve sympathy.

Moreover, respondents believe that Venezuelan migrants are following the health protocols $(59.4 \%)$ and a large plurality $(43.6 \%)$ think that they are no more likely to spread COVID than Colombians. Nor is it the case that Colombians overwhelming think that Venezuelans are using more than their fair share of resources: half of respondents think Venezuelans are not getting more assistance than Colombians, and $43.3 \%$ think that they are not using up scarce health resources. Again, we note that the responses between the new respondents and the panel are statistically indistinguishable from each other. This suggests that there is less heterogeneity between subgroups, something that we find throughout our analyses.

In the bottom panel of Figure 5 we examine how priming respondents to think about COVID first affects answers. The figure plots the difference between receiving the COVID questions before the migration questions and the reverse. Almost all differences are close to zero in size and none are statistically significant. This again suggests that priming COVID has had little impact on opinions towards migration.

In SI Section S7, we also show null effects of receiving the Migration-First question module on the COVID questions that ask about how appropriate the COVID actions taken by the public and the government were (e.g. assessing the national and local governments' COVID19 response). 


\subsection{Heterogeneous Treatment Effects}

Next, we examined whether there are heterogeneous treatment effects based on the health and economics effects of the pandemic in SI Section S6. Overall, our respondents were greatly affected by the pandemic as reported earlier. When comparing between those who had COVID/had a family member with COVID (35.5\% of our sample) versus not, we found no statistically significant effect. ${ }^{27}$ Thus, direct experiences with the pandemic did not changed attitudes towards Venezuelan migrants. Those who fell ill or had sick family members had similar opinions as those who weathered the pandemic better.

We do find support for the indirect economic effects mechanism. The respondents who did not lose their job $(46.1 \%)$ or lose income $(28.3 \%)$ had positive effects for the following questions: their city should host more Venezuelans, there are not too many Venezuelans in Colombia, people should have the right to seek asylum, Venezuelans can integrate successfully, and the presence of Venezuelans makes it easier for Colombians to access public services. This suggests that those who economically better able to weather the pandemic felt more positively towards Venezuelan migrants.

\subsection{Comparison with National Surveys}

While our study provides a contribution by being able to compare pre- and duringCOVID attitudes through a panel survey, a limitation is that our sample is not nationally representative. We focus on Colombians in two major cities. Thus in this section, we compare our sample and results to three nationally representative surveys: the 2020 IPA survey conducted between May and June, the 2020 Latinobarometer survey conducted between November and December, and the 2021 LAPOP survey conducted between March and May.

\footnotetext{
${ }^{27}$ We also examined heterogenous treatment effects for $(1)$ those who are concerned about security worsening due to COVID (41.8\%) versus not; (3) those who report having Venezuelan friends (61.6\%); and (4) those who view Venezuelans as essential workers $(38.3 \%)$ versus not and found no statistically distinguishable differences.
} 
These datasets contain demographic data and information about respondents COVID-19 experiences. Latinobarometer and LAPOP also have data on attitudes toward migration. Although many questions are worded differently in our original survey, we summarize similar questions to put our findings in perspective. Comparisons are reported in SI Section S3.

In general, our sample is similar to IPA, Latinobarometer, and LAPOP in terms of gender: $40.2 \%, 37.2 \%, 47.6 \%, 39.4 \%$ male, respectively. However, our sample is older; the proportion of respondents 55 years old or older is $36.7 \%$, while it is $10.5 \%$ in IPA, $22.4 \%$ in Latinobarometer, and $16.6 \%$ in LAPOP. As for race, most respondents in our sample, Latinobarometer, and LAPOP identify as mestizo: 41.7\%, 44.6\%, and 42.8\%, respectively. Partisanship is similar in our respondents and Latinobarometers; most respondents identify with the center in both surveys (42.2\% and $43.8 \%$, respectively). However, only $10.1 \%$ LAPOPs respondents identify with the center while $37.8 \%$ do not report ideological position. On the other hand, our sample is similar to IPA and Latinobarometer in the proportion of respondents that received government assistance since the pandemic began: $28.3 \%, 28 \%$, and $30.4 \%$, respectively. As for religion, only Latinobarometer included related questions. In this case, $63 \%$ of our respondents and $67.3 \%$ of Latinobarometers are Catholic. IPA was the only survey that included questions on education. The proportion of respondents with secondary or more education is similar in both samples: $71.6 \%$ in ours and $72.5 \%$ in IPAs. We also observe that the proportion of people living in the same place as before the quarantine is similar in our sample (89.6\%) and IPA's nationally representative sample $(95.4 \%)$.

Next, we can compare our findings with Latinobarometer and LAPOP data on attitudes toward migrants. Consistent with our results, we find only $21.7 \%$ of the Latinobarometer 2020 sample is open to receiving more Venezuelan migrants. Likewise, we find that $67.4 \%$ of Latinobarometer respondents think that immigrants come to take their jobs. Although this latter question refers to immigrants in general, we observe a similar share of respondents 
in our sample thinking Venezuelans take Colombian jobs. In line with our results about the perceived benefit of Venezuelans presence in Colombia, we find that $19.3 \%$ of LAPOP respondents think it is good for the Colombian economy that Venezuelans come to live in Colombia. We also see a similar share of respondents linking Venezuelans with securityrelated issues $(80.3 \%$ compared to $74.1 \%)$. Thus, while we conducted our survey in two cities in Colombia, it mirrors national-level experiences with COVID-19 and public opinion towards migrants.

Lastly, we use weights derived from LAPOP. When we reweight the analyses shown above using these nationally representative weights, SI Section S5 shows that our results are substantively unchanged.

\section{Discussion on how Elite Rhetoric might explain why Colombians did not Change their Views}

In this study we found that the majority of our respondents did not change their attitudes towards Venezuelans. For one, this shows how stable attitudes are; even a major shock like a pandemic did little to change views. However, our findings differ from those in the Global North where larger changes in attitudes have been found. We theorize that elite rhetoric scapegoating, or the lack thereof, may play a central role.

In general, scholars have found that negative elite rhetoric can affect attitudes on immigration; for instance, Trump's negative messaging on immigrant during the 2016 campaign increased anti-immigrant sentiment among those who already were prejudiced against immigrants (Flores, 2018). Similarly, Czymara (2020) finds that countries in which elites are more exclusionary had more negative attitudes towards Muslim immigrants. On the other hand, more tolerant messages from elites towards immigrants can foster more tolerant views (Schleiter, Tavits and Ward, 2021). 
Notably, at the onset of the pandemic, Trump and other prominent right-wing politicians and media figures in the Global North started referring to COVID-19 as the "Wuhan virus," "Chinese virus," and "Kung Flu," thereby "othering" and scapegoating Chinese people and the larger Asian/Asian-American communities. It was not only Asian immigrants and AsianAmericans who were targeted during the pandemic, the Trump administration also used the health crisis to stop asylum-seekers, most of who are from Central America, from entering the US under Title 42 even when health officials argued that was unnecessary (Dearen and Burke, 2020).

Studies have also shown that this elite framing can affect opinions during a pandemic. Reny and Barreto (2020) argues that elites were successfully able to tie anti-Asian prejudice and fears about COVID and that concerns about COVID led respondents to say that they would "stay away" from foreigners. Using Twitter data, Chan, Kim and Leung (2021) find that Trump's framing of COVID-19 as the "Chinese virus" normalized and increased anti-Asian sentiment among other political elites and the American public. Also in the US, Adida, Dionne and Platas (2018) find that politicizing the Ebola crisis in 2014 increased stigmatization of African migrants and support for restrictive immigration policies. Similarly, to explain the rise of hate crimes against Asians in Italy, Dipoppa, Grossman and Zonszein (2021) point to mobilization by local far-right leaders and institutions. Political leaders can signal that minorities or immigrants are reasonable targets for anger during a crisis. In turn, this may signal to individuals that they will not be punished, and may even be praised, for attacks on these groups (Dionne and Turkmen, 2020, 25).

In contrast to those in the Global North, Colombian politicians did not scapegoat immigrants for the pandemic. While the Colombian government did close the border between Colombia and Venezuela (and later stopped international flights), the political environment has become more welcoming toward Venezuelans during the pandemic. As noted above, the 
Colombian government announced a moratorium on evictions of Venezuelans and Venezuelans, regardless of status, had access to public health services in case of a COVID-19 infection. $^{28}$

On February 8, 2021, President Duque announced in a joint briefing with U.N. High Commissioner for Refugees Filippo Grandi that the Colombian government will grant temporary legal status to the more than 1.7 million Venezuelan migrants in Colombia. ${ }^{29}$ This status allows them to stay in the country for 10 years, gives them access to health (including COVID-19 vaccines), education, and financial services as well as the right to legally work in Colombia. All Venezuelan migrants who arrived in Colombia before January 31 are eligible, as are those who enter legally during the first two years that the policy is in effect.

Although Duque proposed to create the temporary protected status during his presidential campaign and had started working with the UNHCR on the process not long after assuming office, ${ }^{30}$ this announcement was surprising. We find no media reports anticipating the regularization before its official announcement on February 8, 2021. It was also somewhat surprising because Duque had said that undocumented Venezuelans would not be eligible for the Covid-19 vaccine about six weeks prior to this announcement. ${ }^{31}$ Nonetheless, we find little evidence that national politicians were stoking fears that the Venezuelans were responsible for the pandemic, unlike many right-wing politicians in the Global North.

Our endline survey occurred during a time of high rates of COVID infections and renewed COVID-related restrictions. But at the same time, the national government unexpectedly

\footnotetext{
${ }^{28}$ https://mixedmigration.org/wp-content/uploads/2021/04/167_access_health_services_ Venezuelans_in_Colombia_and_Peru_during_COVID19.pdf In fact, all Venezuelans were eligible for emergency care in Colombia prior to the pandemic. https://www.npr.org/sections/goatsandsoda/ 2019/08/20/751192495/free-health-care-for-venezuelans-in-colombia-isn-t-always-free

${ }^{29}$ UNHCR statement: https://www.unhcr.org/news/press/2021/2/60214cf74/unhcr-iom-welcomecolombias-decision-regularize-venezuelan-refugees-migrants.html

${ }^{30}$ https : //www.csis.org/analysis/discussion-president-iv\%C3\%A1n-duque-grantingtemporary-legal-protection-venezuelan-migrants

${ }^{31}$ https : //www . thenewhumanitarian .org/news-feature/2021/3/10/covid-19-vaccines-mayelude-venezuelan-migrants-in-colombia.
} 
extended a generous regularization policy to migrants. Our results suggest two avenues for future research: first, scholars should examine how much elite rhetoric plays a role in stoking anti-immigrant sentiment during a pandemic. While the BIS theory highlights that the immigrant/minority group needs to be different from the majority group in appearance, we know that elites can create or mitigate those differences (Davenport, 2020; Posner, 2005; Telles and Paschel, 2014). Further analysis of the role of elites is needed. Second, scholars should investigate whether social welfare programs can mitigate the increase in prejudice in times of job and income loss. It may be that these programs need to be normalized to prevent the concern over the loss of status and/or that there needs to be greater emphasis of non-job/income related status.

\section{Conclusion}

In this paper, we examine whether and how the COVID-19 pandemic has changed opinions towards migrants in a major migrant-hosting country within the Global South, Colombia. Using a combination of a panel survey and an embedded survey experiment, we find that COVID largely has not affected Colombians' views towards Venezuelans. While Colombians' hold negative views overall, their views have stayed the same or become slightly more positively disposed to Venezuelan migrants. For those who kept their jobs through the pandemic, their attitudes became even more positive. Thus, the case of attitudes towards Venezuelan migrants in Colombia during COVID-19 is an optimistic story and an example of the dog that didn't bark - there was little to no change in opinion with the pandemic.

What explains why the COVID-19 threat didn’t intensify anti-migrant prejudice, and if anything, slightly increased empathy towards migrants in our case when it did in so many other cases around the world? We believe that our null results may be due to the low levels of negative elite framing of Venezuelans as carriers of disease or as the cause of other 
harms during the pandemic. This is not to say that political elites have not used rhetoric to negatively frame Venezuelans; they have focused on how Venezuelan migrants in Colombia might pull politics towards the left around election time (Holland, Peters and Zhou, 2021). But, they have not done so by explicitly linking COVID to xenophobic fears. Therefore, xenophobia need not follow public health crises. How elites choose to frame refugees and migrants in times of crisis is a critical component, a lens though which everyday citizens will view those migrants.

In many countries in the Global North, prominent politicians have used migrants (and other minoritized groups) as scapegoats for their poor performance during COVID-19. In contrast, the Colombian government's early approach to the virus was viewed as a success ${ }^{32}$ and overall, it has been relatively successful job in stopping transmission, especially when compared to its neighbors, Brazil and Peru. ${ }^{33}$ Furthermore, with respect to Venezuelans, the Colombian government under President Duque did not retract rights for migrants or force them to repatriate. Instead, it announced a massive program to help further regularize Venezuelan migrants and expand their access to rights and services, including healthcare.

Our study leads to several additional questions for future research. First, do our findings replicate in other Global South contexts? As Adamson and Tsourapas (2020) note, there has been a lack of research on migration in the Global South in general, let alone on the social and political consequences of COVID-19. Second, what causes some politicians but not others to use migrants and other minorities as scapegoats during a pandemic? In our case, Colombians already held negative attitudes towards Venezuelans that could have been further activated during the pandemic. And yet, politicians chose not to go this route. Finally, what happens when politicians not only refrain from blaming migrants but actually celebrate them? For example, France has fast-tracked citizenship for immigrant frontline

\footnotetext{
${ }^{32}$ https://www.cgdev.org/publication/covid-19-colombia-impact-and-policy-responses

${ }^{33}$ https : //ourworldindata.org/coronavirus/country/colombia
} 
workers. ${ }^{34}$ Research tying pandemics to xenophobia should also examine cases in which elites have positively framed migrants in times of crisis.

\footnotetext{
${ }^{34}$ https : //www.nytimes . com/2020/12/22/world/europe/france-naturalization-covidfrontline.html
} 


\section{References}

Aarøe, Lene, Michael Bang Petersen and Kevin Arceneaux. 2017. "The behavioral immune system shapes political intuitions: Why and how individual differences in disgust sensitivity underlie opposition to immigration." American Political Science Review 111(2):277-294.

Adamson, Fiona B and Gerasimos Tsourapas. 2020. "The migration state in the global south: Nationalizing, developmental, and neoliberal models of migration management." International Migration Review 54(3):853-882.

Adida, Claire L, Kim Yi Dionne and Melina R Platas. 2018. "Ebola, elections, and immigration: how politicizing an epidemic can shape public attitudes." Politics, Groups, and Identities pp. 1-27.

Bahar, Dany, Ana María Ibáñez and Sandra V Rozo. 2021. "Give me your tired and your poor: Impact of a large-scale amnesty program for undocumented refugees." Journal of Development Economics 151:102652.

Brown, Mitch, Lucas A Keefer, Donald F Sacco and Aaron Bermond. 2019. "Is the cure a wall? Behavioral immune system responses to a disease metaphor for immigration." Evolutionary Psychological Science 5(3):343-356.

Chan, Nathan Kar Ming, Jae Yeon Kim and Vivien Leung. 2021. "COVID-19 and Asian Americans: How Elite Messaging and Social Exclusion Shape Partisan Attitudes." Perspectives on Politics p. $1 ? 17$.

Coates, Melanie. 2020. "Covid-19 and the rise of racism." BMJ 369.

Crawley, Heaven and Dimitris Skleparis. 2018. "Refugees, migrants, neither, both: categorical fetishism and the politics of bounding in Europe's 'migration crisis.'" Journal of Ethnic and Migration Studies 44(1):48-64.

Czymara, Christian S. 2020. "Propagated preferences? Political elite discourses and Europeans? openness toward Muslim immigrants." International Migration Review 54(4):12121237.

Daniels, Chelsea, Paul DiMaggio, G Cristina Mora and Hana Shepherd. 2021. Has Pandemic Threat Stoked Xenophobia? How COVID-19 Influences California Voters Attitudes toward Diversity and Immigration. In Sociological Forum.

Davenport, Lauren. 2020. "The fluidity of racial classifications." Annual Review of Political Science 23:221-240.

Dearen, Jason and Garance Burke. 2020. "Pence ordered borders closed after CDC experts refused." Associated Press .

URL: $\quad$ https://apnews.com/article/virus-outbreak-pandemics-public-health-new-yorkhealth-4ef0c6c5263815a26f8aa17f6ea490ae 
Devakumar, Delan, Geordan Shannon, Sunil S Bhopal and Ibrahim Abubakar. 2020. "Racism and discrimination in COVID-19 responses." The Lancet 395(10231):1194.

Dhanani, Lindsay Y and Berkeley Franz. 2021. "Why public health framing matters: An experimental study of the effects of COVID-19 framing on prejudice and xenophobia in the United States." Social Science \& Medicine 269:113572.

Dionne, Kim Yi and Fulya Felicity Turkmen. 2020. "The Politics of Pandemic Othering: Putting COVID-19 in Global and Historical Context." International Organization 74(S1):E213-E230.

Dionne, Kim Yi and Laura Seay. 2015. "Perceptions about Ebola in America: Othering and the role of knowledge about Africa." PS: Political Science and Politics 48(1):6-7.

Dipoppa, Gemma, Guy Grossman and Stephanie Zonszein. 2021. "Locked Down, Lashing Out: Situational Triggers and Hateful Behavior Towards Minority Ethnic Immigrants." Working Paper.

Dong, Ensheng, Hongru Du and Lauren Gardner. 2020. "An interactive web-based dashboard to track COVID-19 in real time." The Lancet Infectious Diseases 20(5):533-534.

URL: http://www.sciencedirect.com/science/article/pii/S1473309920301201

Douglas, Mary. 1966. Purity and danger: An analysis of concepts of pollution and taboo. Routledge.

Drouhot, Lucas G, Sören Petermann, Karen Schönwälder and Steven Vertovec. 2021. "Has the Covid-19 pandemic undermined public support for a diverse society? Evidence from a natural experiment in Germany." Ethnic and Racial Studies 44(5):877-892.

Esses, Victoria M and Leah K Hamilton. 2021. "Xenophobia and anti-immigrant attitudes in the time of COVID-19." Group Processes 6 Intergroup Relations 24(2):253-259.

Fairchild, Amy L and Eileen A Tynan. 1994. "Policies of containment: immigration in the era of AIDS." American Journal of Public Health 84(12):2011-2022.

Faulkner, Jason, Mark Schaller, Justin H Park and Lesley A Duncan. 2004. "Evolved diseaseavoidance mechanisms and contemporary xenophobic attitudes." Group Processes 85 Intergroup Relations 7(4):333-353.

Flores, René D. 2018. "Can elites shape public attitudes toward immigrants?: Evidence from the 2016 US presidential election." Social Forces 96(4):1649-1690.

Freier, Luisa Feline and Marcia Vera Espinoza. 2021. "COVID-19 and Immigrants Increased Exclusion: The Politics of Immigrant Integration in Chile and Peru." Frontiers in Human Dynamics 3:6.

Freitag, Markus and Nathalie Hofstetter. 2022. "Pandemic threat and intergroup relations: How negative emotions associated with the threat of COVID-19 shape attitudes towards immigrants." Journal of Ethnic and Migration Studies pp. 1-20. 
Gadarian, Shana Kushner, Sara Wallace Goodman and Thomas B Pepinsky. 2022a. Pandemic Politics: The Deadly Toll of Partisanship in the Age of COVID. Princeton University Press.

Gadarian, Shana Kushner, Sara Wallace Goodman and Thomas B Pepinsky. 2022b. "Racial Resentment and Support for COVID-19 Travel Bans in the United States.". Working Paper.

Goldstein, Judith L and Margaret E Peters. 2014. "Nativism or economic threat: Attitudes toward immigrants during the great recession." International Interactions 40(3):376-401.

Green, Eva GT, Franciska Krings, Christian Staerklé, Adrian Bangerter, Alain Clémence, Pascal Wagner-Egger and Thierry Bornand. 2010. "Keeping the vermin out: Perceived disease threat and ideological orientations as predictors of exclusionary immigration attitudes." Journal of Community $\&$ Applied Social Psychology 20(4):299-316.

Hale, Thomas, Anna Petherick, Toby Phillips and Samuel Webster. 2020. "Variation in government responses to COVID-19." Blavatnik school of government working paper 31:202011.

Hamlin, Rebecca. 2021. Crossing: How We Label and React to People on the Move. Stanford University Press.

Hartman, Erin and F Daniel Hidalgo. 2018. "An equivalence approach to balance and placebo tests." American Journal of Political Science 62(4):1000-1013.

Hartman, Todd K, Thomas VA Stocks, Ryan McKay, Jilly Gibson-Miller, Liat Levita, Anton P Martinez, Liam Mason, Orla McBride, Jamie Murphy, Mark Shevlin et al. 2020. "The authoritarian dynamic during the COVID-19 pandemic: effects on nationalism and anti-immigrant sentiment." Social Psychological and Personality Science p. 1948550620978023.

Holland, Alisha C and Margaret E Peters. 2020. "Explaining Migration Timing: Political Information and Opportunities." International Organization pp. 1-24.

Holland, Alisha Caroline, Margaret Peters and Yang-Yang Zhou. 2021. "Left Out: How Political Ideology Affects Support for Migrants in Colombia." Available at SSRN 3803052

Hopkins, Daniel J, Yotam Margalit and Omer Solodoch. 2022. "Personal Economic Shocks and Anti-immigrant Backlash.". Working Paper.

Ibánez, Ana Marıa, Andrés Moya, Marıa Adelaida Ortega, Marisol Rodriguez Chatruc and Sandra V Rozo. 2021. "Life Out of the Shadows: Impacts of Amnesties in Migrant?s Life." Working Paper.

Jillson, Chris. 2020. "Costa Ricas Neighbor, Intruder, and Essential Worker: The Covid19 pandemic has fueled xenophobia against nicaraguan migrants, dovetailing with a long history of discrimination and exclusion." NACLA Report on the Americas 52(4):385-390. 
Kim, Heejung S, David K Sherman and John A Updegraff. 2016. "Fear of Ebola: The influence of collectivism on xenophobic threat responses." Psychological Science 27(7):935944.

Kraut, Alan M. 1995. Silent travelers: Germs, genes, and the immigrant menace. JHU Press.

Kustov, Alexander, Dillon Laaker and Cassidy Reller. 2021. "The stability of immigration attitudes: Evidence and implications." The Journal of Politics 83(4):1478-1494.

Lu, Yao, Neeraj Kaushal, Xiaoning Huang and S Michael Gaddis. 2021. "Priming COVID19 salience increases prejudice and discriminatory intent against Asians and Hispanics." Proceedings of the National Academy of Sciences 118(36).

Malkki, Liisa H. 1995. Purity and exile: Violence, memory, and national cosmology among Hutu refugees in Tanzania. University of Chicago Press.

Markel, Howard. 1999. Quarantine!: East European Jewish Immigrants and the New York City Epidemics of 1892. JHU Press.

Markel, Howard and Alexandra Minna Stern. 2002. "The foreignness of germs: the persistent association of immigrants and disease in American society." The Milbank Quarterly 80(4):757-788.

Marshall, Shantal R and Jenessa R Shapiro. 2018. "When ?scurry? vs.?hurry? makes the difference: Vermin metaphors, disgust, and anti-immigrant attitudes." Journal of Social Issues 74(4):774-789.

Mckiernan-González, John. 2012. Five. Domestic Tensions at an American Crossroads: Bordering on Gender, Labor, and Typhus Control, 1910-1920. In Fevered Measures. Duke University Press pp. 165-197.

Mourad, Lama and Kelsey P Norman. 2020. "Transforming refugees into migrants: institutional change and the politics of international protection." European Journal of International Relations 26(3):687-713.

Ng, Edmond. 2020. "The Pandemic of Hate Is Giving Novel Coronavirus Disease (COVID19) a Helping Hand.".

Peters, Margaret E. 2017. Trading barriers: immigration and the remaking of globalization. Princeton University Press.

Posner, Daniel N. 2005. Institutions and ethnic politics in Africa. Cambridge University Press.

Power, J Gerard. 1995. "Media dependency, bubonic plague, and the social construction of the Chinese other." Journal of Communication Inquiry 19(1):89-110. 
Prati, Gabriele and Luca Pietrantoni. 2016. "Knowledge, risk perceptions, and xenophobic attitudes: Evidence from Italy during the Ebola outbreak." Risk Analysis 36(10):20002010.

Reny, Tyler T and Matt A Barreto. 2020. "Xenophobia in the time of pandemic: othering, anti-Asian attitudes, and COVID-19." Politics, Groups, and Identities pp. 1-24.

Rozo, Sandra V and Juan F Vargas. 2021. "Brothers or invaders? How crisis-driven migrants shape voting behavior." Journal of Development Economics p. 102636.

Schaller, Mark, Damian R Murray and Marlise K Hofer. 2021. "The behavioural immune system and pandemic psychology: the evolved psychology of disease-avoidance and its implications for attitudes, behaviour, and public health during epidemic outbreaks." European Review of Social Psychology pp. 1-37.

Schaller, Mark and Justin H Park. 2011. "The behavioral immune system (and why it matters)." Current directions in psychological science 20(2):99-103.

Schleiter, Petra, Margit Tavits and Dalston Ward. 2021. "Can political speech foster tolerance of immigrants?" Political Science Research and Methods pp. 1-17.

Suhardiman, Diana, Jonathan Rigg, Marcel Bandur, Melissa Marschke, Michelle Ann Miller, Noudsavanh Pheuangsavanh, Mayvong Sayatham and David Taylor. 2021. "On the Coattails of globalization: migration, migrants and COVID-19 in Asia." Journal of Ethnic and Migration Studies 47(1):88-109.

Telles, Edward and Tianna Paschel. 2014. "Who is black, white, or mixed race? How skin color, status, and nation shape racial classification in Latin America." American Journal of Sociology 120(3):864-907.

Villegas, Mauricio García, Camilo García, Natalia Niño, Andrés Henao, José Fernando Mejía, Sebastián Rubiano, Claudia Ordóñez, Héctor Abad Faciolince, Nathaly Rodríguez, Farid Samir Benavides Vanegas et al. 2009. Normas de papel: la cultura del incumplimiento de reglas. Siglo del Hombre Editores.

Wamsler, Steffen, Julian Erhardt, Maximilian Filsinger and Markus Freitag. 2020. "Pandemic Identity: Exposure to Coronavirus and In-Group-Out-Group Relations.".

Yamagata, Mei, Tsukasa Teraguchi and Asako Miura. 2020. "The relationship between infection-avoidance tendencies and exclusionary attitudes toward foreigners: A panel study of the COVID-19 outbreak in Japan.". 